\title{
COVID-19 Salgınında Ergenlerin Sağlığının Korunması ve Sürdürülmesi: Annelerin Perspektifinden
}

\section{Health of Adolescents in the COVID-19 Outbreak: Perspectives from Mothers}

\section{Eyşan Hanzade Umaç ${ }^{1}$ (D), Ayfer Aydın² (D)}

${ }^{1}$ Koç Üniversitesi, Sağlık Bilimleri Enstitüsü, İstanbul, Türkiye

${ }^{2}$ Koç Üniversitesi, Hemşirelik Fakültesi, İstanbul, Türkiye

ORCID ID: E.H.U. 0000-0002-0083-7754; A.A. 0000-0002-2995-361X

Attf/Citation: Umac EH, Aydin A. COVID-19 salgınında ergenlerin sağlığının korunması ve sürdürülmesi: annelerin perspektifinden. Çocuk Dergisi - Journal of Child 2021;21(1):68-73. https://doi.org/10.26650/jchild.2021.1.824786

öz

Amaç: COVID-19 salgını sürecinde ülkelerde salgına yönelik alınan önlemlerin ergenlerin sağlık davranışlarını nasıl etkilediği ve annelerinin gereksinimleri hakkında çok az şey bilinmektedir. Bu çalışma ergenlerin sağlık davranışlarının salgın sürecinden nasıl etkilendiğini ve salgın sürecinin annelerde ne tür gereksinimlere neden olduğunu belirlemeye yönelik gerçekleştirilmiştir.

Gereç ve Yöntem: Veriler 8-31 Mayıs 2020 tarihleri arasında Qualtrics online veri toplama aracı kullanılarak toplanmıştır. Araştırma verilerinin toplanmasında anne ve ergenlerin özelliklerine yönelik soruların yer aldığı "Anne-Çocuk Bilgi Formu" ve "Ergenlerin Sağlığı Koruma ve Sürdürmeye Yönelik Davranışlarının ve Annelerin Gereksinimlerinin Belirlenmesi Anketi" kullanıımıştır.

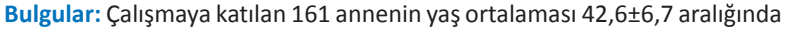
olup ergenlerin \%65,8'i $14-18$ yaş grubunda yer almaktadır. Anneler COVID-19 salgını sürecinde ergenlerin $\% 36,6$ 'sının abur cubur ve $\% 35,6$ 'sının besin tüketiminin arttığııı, \%70,2'sinin fiziksel olarak daha az aktif olduğunu ve \%76,4'ünün geç saatlerde yattığını ifade etmiştir. Ayrıca annelerin $\% 69,6$ 'sının salgın sürecinde çocuğunun sağıı̆ını koruma ve sürdürmeye yönelik bilgi gereksinimi bulunmaktadır.

Sonuç: Annelerin ifadelerine göre ergenlerin sağlık davranışları salgın sürecinden olumsuz etkilenmiştir ve COVID-19 salgını annelerde çocuklarının sağlığııı koruma ve sürdürmeye yönelik bilgi gereksinimine neden olmuştur.

Anahtar Kelimeler: Anneler, COVID-19, SARS-CoV-2, ergen, sağlık davranışı

\section{ABSTRACT}

Objective: During the COVID-19 outbreak, some nationwide measures were taken to slow down and stop the spread of the virus. This study was conducted to determine how health behaviors of adolescents were affected by the outbreak process and what kind of needs the outbreak process caused in mothers.

Material and Method: The data were collected using the Qualtrics online data collection tool between 8-31 May 2020. The "Mother-Child Information Form," including questions on the characteristics of mothers and adolescents, and the "Questionnaire for Determining Adolescents' Behaviors for Protecting and Sustaining the Health and the Needs of Mothers" were used to collect the research data.

Results: The average age of the mothers participating in the study is between $42.6 \pm 6.7 .65 .8 \%$ of adolescents' ages are between 14 and 18 . The mothers indicated that while $36.6 \%$ of adolescents increased their consumption of junk food, $35.6 \%$ of them increased their food consumption, $70.2 \%$ of them were less physically active, and $76.4 \%$ of them slept late during the COVID-19 outbreak. $69.6 \%$ of the mothers have information needs regarding how to protect and maintain their child's health during the outbreak.

Conclusions: As a result of the study, based on the statements of mothers, it was determined that adolescents' health behaviors were negatively affected by the outbreak and that the outbreak caused mothers to have a need for information on protecting and sustaining the health of their adolescent children.

Keywords: Adolescent, COVID-19, SARS-CoV-2, health behavior, mothers

Sorumlu Yazar/Corresponding Author: Eyşan Hanzade Umaç E-mail: eumac14@ku.edu.tr

Başvuru/Submitted: 15.11.2020 • Revizyon Talebi/Revision Requested: 19.02.2021 • Son Revizyon/Last Revision Received: $22.02 .2021 \bullet$ Kabul/Accepted: 17.03.2021 


\section{Giriş̧}

Salgın hastalıklar pek çok çocuk ve ailenin yaşamını fiziksel, sosyal ve psikolojik olarak etkileyebilen nadir fakat yıkıcı krizlerdir. Yıkıcılığını toplum üzerindeki etkisi, ön görülemez olması, ölümler ve beraberinde getirdiği birçok olumsuzluktan alır (1). Aralık 2019'da Çin'in Wuhan şehrinde insanlarda hastalık yapan yeni tip koronavirüsler görülmüş ve hastalığın adı 'COVID-19' olarak adlandırılmıştır. COVID-19 yenidoğan bebekler de dahil olmak üzere her yaştan çocuğa bulaşabilmektedir (2).

COVID-19 gibi pandemi durumlarında okulların kapanması, toplum izolasyonu ve karantina gibi koruyucu önlemler uygulanmaktadır (1). Salgını bastırma amaçlı uygulanan izolasyon ve karantina önlemleri bireylerin sağlığı koruma ve sürdürmeye yönelik davranışlarını etkileyebilmektedir (3). Pandemi sürecinin günlük yaşamında değişikliğe sebep olduğu gruplardan biri özellikle okul çağında olan çocuklar ve ergenlerdir. Salgın sürecinde uygulanan koruyucu önlemler ile salgın sırasındaki ölümlerin, bulaş hızının ve vaka sayısının azalması amaçlanır. Fakat uzmanlar bu önlemlerin çocuk ve ergenlerin fiziksel ve psikososyal sağlıkları üzerinde olumsuz etkilerinin olabileceği görüşündedir (1,3-5).

COVID-19 salgının ergenlere yönelik kanıtları henüz erken aşamada olmakla birlikte geçmiş deneyimler kriz ve sosyal kargaşa zamanlarının tüm çocukları savunmasız bırakabileceğini düşündürmektedir (6). Pandemi döneminde çocukların sağlığını olumsuz etkileyen durumlar ebeveynler için de endişeye neden olmaktadır $(7,8)$. Ebeveynler doğru yaklaşım ile çocuğun yaşadığı duygusal ve fiziksel sorunlara yardımcı olabilecek en yakın ve etkili kişilerdir $(1,9,10)$.

Kaytez ve arkadaşlarının çalışmasında ailenin içinde bulunduğu olumsuz durumun etkilerinin azaltılmasında aile gereksinimlerinin belirlenmesinin önemli olduğu belirtilmiştir (11). Ergenler salgın sürecinde sağlık çalışanları, aileleri ve eğitimciler tarafindan uygun şekilde desteklenerek sıkıntılı sürecin üstesinden gelebilir, duygusal ve fizyolojik anlamda korunabilirler $(6,12)$. Bu doğrultuda çalışmaların planlanması için ebeveynlerin bu süreçte ne tür gereksinimlerinin olduğunun belirlenmesi gerekmektedir. Pandemi sebebiyle beklenmedik bir durum ile karşı karşıya olan ergen sağlığının korunması ve sürdürülmesi için anneler ile etkileşimde olunması bu konuda atılacak öncelikli adımlardandır. Bu çalışma salgın sürecinde ergenlerin sağlık davranışlarında görülen değişiklikleri ve salgın sürecinin annelerde ne tür gereksinimlere neden olduğunu belirlemek amacıyla gerçekleştirilmiştir.

\section{YÖNTEM VE GEREÇ}

Veriler 8-31 Mayıs 2020 tarihleri arasında WhatsApp ve e-mail yolu ile annelere ulaşılarak toplanmıştır. Araştırmaya okuma yazması olan, 18 yaşından büyük ve ergenlik döneminde en az bir çocuğa sahip anneler dahil edilmiştir.

\section{Verilerin toplanması}

Verilerin toplanmasında araştırmacılar tarafindan literatürden faydalanılarak hazırlanan annelerin ve ergenlerin demografik özelliklerine yönelik soruların yer aldığı "Anne-Çocuk Tanıtıcı Bilgi Formu" ve salgın sürecinde ergenlerin sağlık davranışlarındaki değişimi ve annelerin gereksinimlerini belirlemeye yönelik "Ergenlerin Sağ|ığı Koruma ve Sürdürmeye Yönelik Davranışlarının ve Annelerin Gereksinimlerinin Belirlenmesi Anketi" kullanılmıştır $(6,13,14)$. Çalışma öncesinde 10 farklı uzmandan görüş alınarak soruların uygunluğu ve anlaşılırlığı değerlendirilmiştir.

\section{İstatistiksel Analiz}

İstatistiksel analizler SPSS (Statiscal Package For Social Sciences) 25.0 istatistik paket programı kullanılarak yapılmıştır. Tanımlayıcı verilerin dağılımını göstermek için sayı ve yüzdelikler kullanılmıştır. Ergenlerin cinsiyet ve yaş özelliklerinin sağlık davranışlarına göre farklılıkları incelemek için ki-kare testi uygulanmıştır. $P$ değeri $<0,05$ ise analiz istatiksel olarak anlamlı kabul edilmiştir.

\section{BULGULAR}

Çalışmaya toplamda 161 anne katılmıştı ve yaş ortalamala-

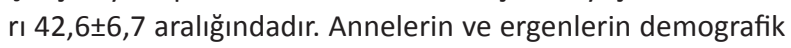
özellikleri Tablo 1'de yer almaktadır.

Tablo 1: Anne ve Ergenlerin Tanıtıcı Özelliklerine Göre Dağılımı.

\begin{tabular}{lc}
\hline Annelerin Tanıtıcı Özellikleri & $\begin{array}{c}\mathbf{N = 1 6 1} \\
\mathbf{n}(\%)\end{array}$ \\
\hline $\begin{array}{l}\text { Medeni Durum } \\
\text { Evli } \\
\text { Bekar }\end{array}$ & $140(87)$ \\
Algılanan Gelir Durumu & $21(13)$ \\
$\quad$ Düşük & \\
Orta & $29(18)$ \\
Yüksek & $100(62,1)$ \\
CovıD-19 Sürecinde Çalışma Durumu & $32(19,9)$ \\
Çalışıyor & \\
Çalışmıyor & $79(49,2)$
\end{tabular}

Ergenlerin Tanıtıcı Özellikleri

Yaş

11-13

14-18

Cinsiyet

$\mathrm{Kız}$

Erkek

Kronik Hastalık Durumu

Yok

$145(90,1)$

Astım

Kalp Hastalığı

Diyabet

Kas Hastalıkları

$1(0,6)$

Beden Kitle İndeksi

Zayıf

Normal

$114(70,8)$

Fazla Kilolu

21 (13)

Şişman/Obez 


\section{Ergenlerin COVID-19 Salgını Sürecinde Sağlık Davranışları} Annelerin ifadelerine göre salgın sürecinde ergenlerde günlük ortalama ekran süresinin 4,90+2,81 olduğu bulunmuştur. Ergenlerin COVID-19 salgını sürecinde beslenme, fiziksel aktivite, uyku, stresle baş etme, kişiler arası ilişkiler ve aktivite davranışlarına yönelik bulgular Tablo 2'de yer almaktadır. Çalışmamızda ergenlerin beslenme, fiziksel aktivite, uyku düzeni, kişiler arası ilişkiler davranışlarındaki değişimler ile ergenlerin yaş ve

\section{Tablo 2: Ergenlerin COVID-19 Salgını Sürecinde Sağlığı Koruma ve Sürdürmeye Yönelik Uygulamalarının Incelenmesi.}

\begin{tabular}{|c|c|}
\hline $\begin{array}{l}\text { Sağlığı Koruma ve Sürdürmeye } \\
\text { Yönelik Davranışlar }\end{array}$ & $\begin{array}{l}N=161 \\
\mathrm{n}(\%)\end{array}$ \\
\hline \multicolumn{2}{|l|}{ Beslenme* } \\
\hline Daha çok yiyecek tüketimi & $57(35,6)$ \\
\hline İştahta azalma & $14(8,7)$ \\
\hline Geç saatte yemek yeme & $32(19,9)$ \\
\hline Ara öğün sayısında artma & $28(17,4)$ \\
\hline Abur cubur tüketiminde artma & $59(36,6)$ \\
\hline \multicolumn{2}{|l|}{ Fiziksel aktivite* } \\
\hline Aktivitesi arttı & $6(4,1)$ \\
\hline Aktivitesi azaldı & $119(74,8)$ \\
\hline Düzenli egzersiz yapıyor & $10(6,2)$ \\
\hline Değişmedi & $26(14,2)$ \\
\hline \multicolumn{2}{|l|}{ Uyku* } \\
\hline Geç yatıyor & $123(76,4)$ \\
\hline Az uyuyor & $7(4,3)$ \\
\hline Çok uyuyor & $29(18)$ \\
\hline Uykuya dalmada güçlük & $19(11,8)$ \\
\hline Sık kabus görüyor & $2(1,2)$ \\
\hline Değişmedi & $27(16,8)$ \\
\hline \multicolumn{2}{|l|}{ Stresle başetme* } \\
\hline \multicolumn{2}{|l|}{ Davranış değişiklikleri } \\
\hline Davranış değişikliği olmadı & $81(50,3)$ \\
\hline İçe kapanık & $13(8,1)$ \\
\hline Anne babaya aşırı bağımlılık & $18(11,2)$ \\
\hline Endişeli & $38(23,6)$ \\
\hline Agresif/sinirli & $47(29,2)$ \\
\hline Uykulu & $17(11,8)$ \\
\hline Mide/baş ağrısı & $8(5)$ \\
\hline Sürekli hastalık korkusu & $12(7,5)$ \\
\hline \multicolumn{2}{|l|}{ Kişiler arası ilişki } \\
\hline Daha çok iletişim kuruyor & $19(12,5)$ \\
\hline Daha az iletişim kuruyor & $74(45,3)$ \\
\hline Değişmedi & $68(42,2)$ \\
\hline \multicolumn{2}{|l|}{ Eğlence/aktivite } \\
\hline \multicolumn{2}{|l|}{ Günlük ekran süresi } \\
\hline $0-2$ saat/gün & $35(21,7)$ \\
\hline 2 saatten fazla & $126(78,3)$ \\
\hline
\end{tabular}

*Kişi davranış seçeneklerinden çoklu seçim yapabilmektedir. cinsiyet özellikleri incelenmiş olup sağlık davranışları ile ergen yaş ve cinsiyet özellikleri arasında anlamlı bir fark bulunmamıştır. Yalnızca 14-18 yaş grubundaki ergenlerin davranış değişikliği görülme sıklığının 11-13 yaş grubuna göre daha fazla olduğu bulunmuştur (Tablo 3).

\section{COVID-19 Salgını Sürecinde Annelerin Gereksinimleri}

Çalışmaya katılan annelerin \%69,6'sı ergenlik döneminde olan çocuklarının sağlığını koruma ve sürdürmeye yönelik bilgi gereksinimleri olduğunu ifade etmiştir. Annelerin bilgi gereksinimi duyduğu konular başlıca zamanı etkili kullanma, fiziksel aktivite ve stresle baş etmedir (Tablo 4).

\section{TARTIŞMA}

Ergenlik döneminde büyüme ve gelişmenin sağlıklı olarak gerçekleşmesinde, bilişsel kapasitenin artmasında ve hastalıklardan korunmada sağlık davranışları önemli bir role sahiptir. Salgın süreci ergenlerin beslenme, fiziksel aktivite, uyku, stres yönetimi ve kişiler arası ilişki davranışlarını olumsuz etkilemiştir. Salgın sürecinde çocuk ve ergenlerin sağlık davranışlarını incelemeye yönelik yapılan çalışmalarda abur cubur tüketiminde ve ögün sayısında artış oldu, fiziksel aktivite davranışlarında ise azalma olduğu bildirilmiştir $(15,16)$. Çalışmamızın salgın sürecinde ergenlerin beslenme ve fiziksel aktivite davranışlarına yönelik bulguları literatür ile uyumludur. Okulun ergenlerin yaşamında düzen sağlaması, fiziksel aktivite ve beslenme düzenine olumlu etki etmesi, ergenlerin evde geçiridği zamanın uzamasıyla dengesiz beslenme alışkanlıklarına yönelimini arttırmış olabilir. Salgın sırasında virüs yayılımını yavaşlatmak için alınan önlemlerin (okulların kapatılması ve ev izolasyonu) ergenlerin fiziksel aktivite/egzersiz davranışlarını sınırlandırması, ergenlerin evde spor alışkanlıklarının olmaması ya da fiziksel enerji harcamayı gerektirmeyen aktiviteleri tercih etmeleri ve ev ortamının spor için uygun olamayacağı gibi durumların salgın sürecinde fiziksel aktivitelerindeki azalmanın sebebi olabileceği düşünülmektedir.

Ergenler evde oldukları sürenin önemli bir kısmını ekrana maruz kalarak geçirmektedir. Pietrobelli ve arkadaşlarının çalışmasında ekran süresinin salgın sürecinde ortalama $7.61 \pm 2.13$ saat/günde olduğu bildirilmiştir (15). Benzer şekilde, Xiang ve arkadaşlarının çalışmasında da ekran süresinin salgın sürecinde arttğı vurgulanmaktadır (16). Günümüzde teknolojinin hemen herkes için erişilebilir hale gelmesi, ergenlerde yaygın cep telefonu ve bilgisayar kullanımının artması ve okulların kapalı olmasıyla evde kalınan sürenin artmasının sonuçlarda etkili olduğu söylenebilir. Okulların kapatılması çocukların arkadaşları ve öğretmenleri ile geçirdiği zamanı önemli oranda etkilemiştir. Çin'de salgın sürecinde yapılan çalışmada salgına yönelik alınan önlemlerin çocuk ve ergenlerde arkadaşlar ile iletişimi azaltacağı vurgulanmaktadır (5).

Kriz ve kargaşa dönemlerinin bireylerin stresle baş etme becerilerinde ve kişiler arası ilişkilerinde değişikliklere neden olduğu bilinmektedir. Çin'de salgından etkilenen çocuk ve ergenlerin yaklaşık \%27'sinde endişeli, \%32'sinde sinirli davranış değişikliği olduğu görülmüştür. Aynı çalışmada anne ve babaya aşırı bağımlılık çocuklarda en çok görülen davranış 
Tablo 3: Adölesanların Sosyodemografik Özellikleri ile Sağlık Davranışlarının İncelenmesi.

\begin{tabular}{|c|c|c|c|c|c|c|c|c|}
\hline \multirow[b]{2}{*}{ Sağlık Davranışı } & \multicolumn{2}{|c|}{ Cinsiyet } & \multirow[b]{2}{*}{$x^{2}$} & & \multicolumn{2}{|c|}{ Yaş } & \multirow[b]{2}{*}{$\mathrm{x}^{2}$} & \multirow[b]{2}{*}{$\mathbf{p}$} \\
\hline & Kız & Erkek & & & $11-13$ & $14-18$ & & \\
\hline \multicolumn{9}{|c|}{ Beslenmede değişiklik } \\
\hline Var & 64 & 48 & & & 41 & 71 & & \\
\hline Yok & 21 & 28 & 2,79 & 0,09 & 14 & 35 & 0,97 & 0,32 \\
\hline \multicolumn{9}{|c|}{ Fiziksel aktivitede değişiklik } \\
\hline Var & 75 & 61 & 3,34 & 0,12 & 48 & 88 & 0,79 & 0,76 \\
\hline Yok & 10 & 15 & & & 7 & 18 & & \\
\hline \multicolumn{9}{|c|}{ Uyku düzeni değişikliği } \\
\hline Var & 71 & 63 & 0,01 & 0,91 & 46 & 88 & 0,92 & 0,10 \\
\hline Yok & 14 & 13 & & & 9 & 18 & & \\
\hline \multicolumn{9}{|c|}{ Arkadaşlar ile iletişimde değişiklik } \\
\hline Var & 45 & 48 & 1,71 & 0,19 & 29 & 64 & 0,86 & 0,35 \\
\hline Yok & 40 & 28 & & & 26 & 42 & & \\
\hline \multicolumn{9}{|c|}{ Davranış değişikliği } \\
\hline Var & 41 & 38 & 0,50 & 0,82 & 21 & 58 & 3,96 & $0,04^{*}$ \\
\hline Yok & 44 & 38 & & & 34 & 48 & & \\
\hline
\end{tabular}

*Kruskal Wallis Test; $p<0.05$

Tablo 4: Annelerin COVID-19 Salgın Sürecinin Yönetimine iliş̧kin Uygulamaları ve Gereksinimlerinin Dağılımı.

\begin{tabular}{ll}
\hline Annelerin Gereksinimleri & $\begin{array}{l}\mathbf{N}=161 \\
\mathbf{n}(\%)\end{array}$ \\
\hline $\begin{array}{l}\text { Çocuğunun sağlığını koruma ve sürdürmeye } \\
\text { yönelik bilgi gereksinimi olan anneler }\end{array}$ & $112(69,9)$ \\
Bilgi gereksinimi olan konular* & \\
Yeterli ve dengeli beslenme & $29(18)$ \\
Düzenli ve yeterli uyku & $37(23)$ \\
Fiziksel aktivite/spor/egzersiz & $46(28,6)$ \\
Stresle baş etme & $43(26,7)$ \\
Zamanı etkili kullanma & $58(36)$ \\
Hastalık ve hastalıktan korunma & $22(13,7)$ \\
Hijyen uygulamaları & $16(9,9)$ \\
Annelerin bilgi kaynağı tercihleri* & $14(8,8)$ \\
Internet & $23(14,3)$ \\
Televizyon & $52(32,3)$ \\
Komşu ve akrabalar & $138(85,7)$ \\
Gazete & $135(83,9)$ \\
\hline
\end{tabular}

*Kişi davranış seçeneklerinden çoklu seçim yapabilmektedir.

değişiklidir (5). Çalışmamızda çocukların anne ve babaya aşırı bağımlı olma hali nispeten düşük oranda gözlenmiştir. Farklılığın örneklem grupları arasındaki yaş aralığından kaynaklı olabileceği düşünülmüştür. Yine farklı bir çalışmada, salgın sürecinde ergenlerin \%18,9'unda anksiyete varlığı bildirilmiştir
(17). Çalışmamız literatürde henüz sınırlı sayıda olan çalışmalar ile benzerlik göstermektedir. Ergenlerde görülen davranış değişiklikleri beklenmedik bir olayla karşı karşıya kalan genç bireylerin çeşitli stres reaksiyonları olarak değerlendirilebilir. Ergenlerde görülen davranış değişikliklerini daha iyi anlamak için bu konuda daha fazla çalışmaya ihtiyaç vardır.

Sağıık davranışları bireylerin cinsiyetlerine ve yaşına göre değişiklik gösterebilmektedir $(18,19)$ fakat çalışmamızın cinsiyet özelliğine bağlı sonuçları literatür ile farkılık göstermektedir. Salgın sürecinin tüm ergenlerin fiziksel aktivite davranışlarını sınırlandırması, tüm yaş gruplarındaki çocukların okula gidememelerinden dolayı arkadaşları ile temas eksikliği yaşamalarının sonuçlarda etkili olduğu düşünülmüştür. Chen ve arkadaşlarının salgın sürecinde ergenlerin yaş aralığına bağlı olarak depresyon ve anksiyete davranışlarını inceledikleri çalışmada 13-15 yaş grubunda görülen depresyon ve anksiyete davranışlarının 9-12 yaş grubundan fazla olduğu bulunmuştur (17). Zhou ve arkadaşlarının 12-18 yaş aralığındaki ergenlerle yaptıkları çalışmalarında da yaş arttıkça depresif davranışta ve anksiyete görülme oranında artış olduğu bulunmuştur (19). Ergenlik döneminde yaşla beraber artş̧ gösterebilen duygusal değişikliklerin yaş grupları arasında görülen farklılığın sebebi olabileceği düşünülmüştür.

COVID-19 ilk kez deneyimlene, etkileri ve tedavisi netlik kazanmamış durumda olan bir salgın hastalıktır. Taşıdığı belirsizlik toplumda çeşitli gereksinimlere neden olabilmektedir. Salgın süreci annelerde çocuğunun sağlığını koruma ve sürdürmeye yönelik bilgi gereksinimine sebep olmuştur. Mücadele etmekte olduğumuz COVID-19 salgınına yeni tip bir koronavirüsün sebep olması ve salgına yönelik bilgilerin henüz tam olarak 
netlik kazanmamış olması annelerin bilgi gereksinimini açıklar niteliktedir. Toplumsal bir konu olan COVID-19 salgınına yönelik televizyonda düzenli olarak güncel veri ve bilgilerin paylaşıllyor olmasının ise annelerin bilgiye ulaşmada medya araçlarına yönelimini etkilediği söylenebilir.

Annelerin bilgi gereksinimi duyduğu konuların dağııımında ise çocuklarında görülen sağlık davranışlarında günlük ekran süresinin artması, fiziksel aktivite azlığı, salgın sürecinde görülen davranış değişikliklerinin sebep olduğu düşünülmüştür.

\section{Çalışmanın Sınırlııkları}

Salgın sürecinin getirdiği sınırlamalar nedeniyle verilerin anne ifadelerine dayanıyor olması çalışmanın sınırıılıkları arasında yer almaktadır.

\section{SONUÇ}

Sonuçlar salgın sürecinde ergen sağ|lğııı koruma ve sürdürmeye yönelik programların geliştirilmesi gerektiğini düşündürmektedir. Ailelerin çocukları ile birlikte evde yapabilecekleri aktivite ve egzersiz konularında bilgilendirilmesi, okulların kapalı olması ve ekran süresinin artmasından etkilenen uyku düzeni için düzenlemelerin yapılması, ergenlerde meydana gelen davranış değişikliklerinin yakından takip edilmesi, online danışmanlık hizmetlerinin sağlanması ve eğitim materyallerinin oluşturulması önerilmektedir. Uzmanlara ise daha fazla sayıda örneklem içeren çalışmaların yapılması önerilmektedir.

Etik Komite Onayı: Bu çalışma için etik kurul onayı Koç Üniversitesi Sosyal Bilimler Araştırmaları Etik Kurulu’ndan alınmıştır (2020.205. IRB3.085).

Bilgilendirilmiş Onam: Katılımcılardan bilgilendirilmiş onam alınmıştır

Hakem Değerlendirmesi: Dış bağımsız.

Yazar Katkıları: Çalışma Konsepti/Tasarım- E.H.U., A.A.; Veri ToplamaE.H.U., A.A.; Veri Analizi/Yorumlama- E.H.U., A.A.; Yazı Taslağı- E.H.U., A.A.; İçeriğin Eleştirel İncelemesi- E.H.U., A.A.; Son Onay ve SorumlulukE.H.U., A.A.

Çıkar Çatışması: Yazarlar çıkar çatışması beyan etmemişlerdir.

Finansal Destek: Yazarlar finansal destek beyan etmemişlerdir.

Ethics Committee Approval: This study was approved by Koç University Social Sciences Research Ethics Committee. (2020.205.IRB3.085).

Informed Consent: Written consent was obtained from the participants.

Peer Review: Externally peer-reviewed.

Author Contributions: Conception/Design of Study- E.H.U., A.A.; Data Acquisition- E.H.U., A.A.; Data Analysis/Interpretation- E.H.U., A.A.; Drafting Manuscript- E.H.U., A.A.; Critical Revision of ManuscriptE.H.U., A.A.; Final Approval and Accountability- E.H.U., A.A.

Conflict of Interest: Authors declared no conflict of interest.

Financial Disclosure: Authors declared no financial support.

\section{KAYNAKLAR/REFERENCES}

1. Sprang G, Silman M. Posttraumatic stress disorder in parents and youth after health-related disasters. Disaster Med Public Health Prep 2013;7(1):105-10. DOI: 10.1017/dmp.2013.22.

2. Dong $\mathrm{Y}, \mathrm{Mo} X, \mathrm{Hu} Y$, Qi $X$, Jiang F, Jiang $Z$, et al. Epidemiology of COVID-19 Among Children in China. Pediatrics 2020;145(6). DOI: 10.1542/peds.2020-0702.

3. Viner RM, Russell SJ, Croker H, Packer J, Ward J, Stansfield C, et al. School closure and management practices during coronavirus outbreaks including COVID-19: a rapid systematic review. Lancet Child Adolesc Health 2020;4(5):397-404. DOI: 10.1016/S2352-4642(20)30095-X.

4. Golberstein E, Wen H, Miller BF. Coronavirus Disease 2019 (COVID-19) and Mental Health for Children and Adolescents. JAMA Pediatr 2020;174(9):819-20. DOI: 10.1001/jamapediatrics.2020.1456.

5. Jiao WY, Wang LN, Liu J, Fang SF, Jiao FY, Pettoello-Mantovani M, et al. Behavioral and Emotional Disorders in Children during the COVID-19 Epidemic. J Pediatr 2020;221:264-6 e1. DOI: 10.1016/j. jpeds.2020.03.013.

6. UNICEF. Coronavirus (COVID-19) guide for parents 2020 Available from: Available from: https://www.unicef.org/parenting/ coronavirus-covid-19-guide-parents.

7. Ercan ES, Arman AR, Emiroğlu NI, Öztop DB, Yalçın Ö. Türkiye Çocuk ve Genç Psikiyatrisi Derneği COVID-19 Virüs Salgını Sırasında Aile, Çocuk ve Ergenlere Yönelik Psikososyal ve Ruhsal Destek Rehberi. 2020 (12/12/2020). Available from: https://www.ankara.edu.tr/ covid-19-virus-salgini-sirasinda-aile-cocuk-ve-ergenlere-yonelikpsikososyal-ve-ruhsal-destek-rehberi/.

8. Sinha IP, Harwood R, Semple MG, Hawcutt DB, Thursfield R, Narayan O, et al. COVID-19 infection in children. Lancet Respir Med 2020;8(5):446-7. DOI: 10.1016/S2213-2600(20)30152-1.

9. Shahhosseini Z, Simbar M, Ramezankhani A, Majd HA. Supportive family relationships and adolescent health in the socio-cultural context of Iran: a qualitative study. Ment Health Fam Med 2012;9(4):251-6.

10. Perrin EC, Leslie LK, Boat T. Parenting as Primary Prevention. JAMA Pediatr2016;170(7):637-8.DOI:10.1001/jamapediatrics.2016.0225.

11. Kaytez N, Durualp E, Kadan G. Engelli çocuğu olan ailelerin gereksinimlerinin ve stres düzeylerinin incelenmesi. Eğitim ve Öğretim Araştırmaları Dergisi 2015;4(1):197-214. Available from: http://jret.org/FileUpload/ks281142/File/19.kaytez.pdf.

12. Pettoello-Mantovani M, Pop TL, Mestrovic J, Ferrara P, Giardino I, Carrasco-Sanz A, et al. Fostering Resilience in Children: The Essential Role of Healthcare Professionals and Families. J Pediatr 2019;205:e1298-9. DOI: 10.1016/j.jpeds.2018.10.069.

13. Brooks SK, Webster RK, Smith LE, Woodland L, Wessely S, Greenberg N, et al. The psychological impact of quarantine and how to reduce it: rapid review of the evidence. The Lancet 2020;395(10227):912-20. DOI: https://doi.org/10.1016/S01406736(20)30460-8.

14. Chen P, Mao L, Nassis GP, Harmer P, Ainsworth BE, Li F. Returning Chinese school-aged children and adolescents to physical activity in the wake of COVID-19: Actions and precautions. J Sport Health Sci 2020;9(4):322-4. DOI: 10.1016/j.jshs.2020.04.003.

15. Pietrobelli A, Pecoraro L, Ferruzzi A, Heo M, Faith M, Zoller T, et al. Effects of COVID-19 Lockdown on Lifestyle Behaviors in Children with Obesity Living in Verona, Italy: A Longitudinal Study. Obesity (Silver Spring) 2020;28(8):1382-5. DOI: 10.1002/oby.22861. 
16. Xiang M, Zhang Z, Kuwahara K. Impact of COVID-19 pandemic on children and adolescents' lifestyle behavior larger than expected. Prog Cardiovasc Dis 2020;63(4):531-2. DOI: 10.1016/j. pcad.2020.04.013.

17. Chen F, Zheng D, Liu J, Gong Y, Guan Z, Lou D. Depression and anxiety among adolescents during COVID-19: A cross-sectional study. Brain Behav Immun 2020;88:36-8. DOI: 10.1016/j. bbi.2020.05.061.
18. He K, Kramer E, Houser RF, Chomitz VR, Hacker KA. Defining and understanding healthy lifestyles choices for adolescents. J Adolesc Health 2004;35(1):26-33. DOI: 10.1016/j.jadohealth.2003.09.004.

19. Zhou SJ, Zhang LG, Wang LL, Guo ZC, Wang JQ, Chen JC, et al. Prevalence and socio-demographic correlates of psychological health problems in Chinese adolescents during the outbreak of COVID-19. Eur Child Adolesc Psychiatry 2020;29(6):749-58. DOI: 10.1007/s00787-020-01541-4. 